\title{
Estimation of Admission D-dimer Cut-off Value to Predict Venous Thrombotic Events in Hospitalized COVID-19 Patients: Analysis of the SEMI-COVID-19 Registry
}

\author{
Carles García-Cervera, $M D^{7}{ }^{(10}$, Vicente Giner-Galvañ, $M D, P h D^{1,2,3}$, \\ Philip Wikman-Jorgensen, $M D, P h D^{1,3}$, Jaime Laureiro, $M D^{4}$, \\ Manuel Rubio-Rivas, MD, $P h D^{5}$, Anthony Gurjian Arena, $M D^{6}$, \\ Francisco Arnalich-Fernandez, MD, PhD 7 , José Luis Beato Pérez, MD ${ }^{8}$, \\ Juan Antonio Vargas Núñez, MD, $P h D^{9}$, Jesús Javier González lgual, $M D^{10}$, \\ Jesús Díez-Manglano, MD, PhD ${ }^{17}$, Manuel Méndez Bailón, MD, PhD ${ }^{12}$, \\ María José García Blanco, $\mathrm{MD}^{13}$, Santiago J. Freire Castro, $\mathrm{MD}^{14}$, \\ Judit Aranda Lobo, MD ${ }^{75}$, Luis Manzano, MD, $\mathrm{PhD}^{16}$, \\ Jeffrey Oskar Magallanes Gamboa, MD" ${ }^{17}$, Luis Arribas Pérez, MD ${ }^{18}$, \\ Julio González Moraleja, MD, PhD ${ }^{19}$, Ruth Calderón Hernaiz, MD20, \\ Javier García Alegría, MD²1, Amara González Noya, MD², \\ Ricardo Gómez Huelgas, MD, PhD ${ }^{23}$, Carlos Lumbreras Bermejo ${ }^{4}$, and \\ Juan Miguel Antón Santos ${ }^{20}$ for the SEMI-COVID-19 Network
}

\footnotetext{
'General Internal Medicine Department, Hospital Universitario San Juan de Alicante, San Juan de Alicante, Alicante, Spain; ${ }^{2}$ Department of Clinical Medicine, Faculty of Medicine, Miguel Hernández University, Elche, Alicante, Spain; ${ }^{3}$ Fundación para el Fomento de la Investigación Sanitaria y Biomédica de la Comunitat Valenciana (FISABIO), Conselleria de Sanitat, Generalitat Valenciana, Valencia, Spain; ${ }^{4}$ Internal Medicine Department, 12 de Octubre University Hospital, Madrid, Spain; Internal Medicine Department, Bellvitge University Hospital-IDIBELL, Barcelona, Spain; IInternal Medicine Department, Gregorio Marañon University Hospital, Madrid, Spain; 'Internal Medicine Department, La Paz University Hospital, Madrid, Spain; ${ }^{8}$ Internal Medicine Department, Albacete University Hospital Complex, Albacete, Spain; ${ }^{9}$ Internal Medicine Department, Puerta de Hierro University Hospital, Majadahonda, Madrid, Spain; ${ }^{10}$ Internal Medicine Department, Miguel Servet Hospital, Zaragoza, Spain;

${ }^{11}$ Internal Medicine Department, Royo Villanova Hospital, Zaragoza, Spain; ${ }^{2}$ Internal Medicine Department, San Carlos Clinical Hospital, Madrid, Spain; ${ }^{13}$ Internal Medicine Department, La Princesa University Hospital, Madrid, Spain; ${ }^{14}$ Internal Medicine Department, A Coruña University Hospital, A Coruña, Spain; ${ }^{15}$ Internal Medicine Department, Consorci Sanitari Integral - Moisès Broggi Hospital, Sant Joan Despí, Barcelona, Spain; ${ }^{16}$ Internal Medicine Department, Ramón y Cajal University Hospital, IRYCIS, Madrid, Spain; ${ }^{17}$ Internal Medicine Department, Nuestra Señora del Prado Hospital, Talavera de la Reina, Toledo, Spain; ${ }^{18}$ Internal Medicine Department, Zamora Hospital Complex, Zamora, Spain; ${ }^{19}$ Internal Medicine Department, Virgen de la Salud Hospital, Toledo, Spain; ${ }^{20}$ Internal Medicine Department, Infanta Cristina University Hospital, Parla, Madrid, Spain; ${ }^{21}$ Internal Medicine Department, Costa del Sol Hospital, Marbella, Málaga, Spain; ${ }^{22}$ Internal Medicine Department, Ourense University Hospital Complex, Ourense, Spain; ${ }^{23}$ Internal Medicine Department, Regional University Hospital of Málaga, Biomedical Research Institute of Málaga (IBIMA), University of Málaga (UMA), Málaga, Spain.
}

BACKGROUND: Venous thrombotic events (VTE) are frequent in COVID-19, and elevated plasma D-dimer (pDd) and dyspnea are common in both entities.

OBJECTIVE: To determine the admission pDd cut-off value associated with in-hospital VTE in patients with COVID-19.

METHODS: Multicenter, retrospective study analyzing the at-admission pDd cut-off value to predict VTE and anticoagulation intensity along hospitalization due to COVID-19.

RESULTS: Among 9386 patients, 2.2\% had VTE: $1.6 \%$ pulmonary embolism (PE), $0.4 \%$ deep vein thrombosis (DVT), and $0.2 \%$ both. Those with VTE had a higher prevalence of tachypnea (42.9\% vs. $31.1 \%$; $=0.0005$ ), basal O2 saturation <93\% (45.4\% vs. 33.1\%; $\mathrm{p}=0.0003$ ), higher

Received February 1, 2021

Accepted June 29, 2021

Published online July 21, 2021 at admission pDd (median [IQR]: 1.4 [0.6-5.5] vs. 0.6 [0.4-1.2] $\mu \mathrm{g} / \mathrm{ml} ; \mathrm{p}<0.0001$ ) and platelet count (median [IQR]: 208 [158-289] vs. 189 [148-245] platelets $\times 10^{9} /$ $\mathrm{L} ; \mathrm{p}=0.0013$ ). A pDd cut-off of $1.1 \mu \mathrm{g} / \mathrm{ml}$ showed specificity $72 \%$, sensitivity $49 \%$, positive predictive value (PPV) 4\%, and negative predictive value (NPV) 99\% for in-hospital VTE. A cut-off value of $4.7 \mu \mathrm{g} / \mathrm{ml}$ showed specificity of $95 \%$, sensitivity of $27 \%$, PPV of $9 \%$, and NPV of 98\%. Overall mortality was proportional to pDd value, with the lowest incidence for each pDd category depending on anticoagulation intensity: $26.3 \%$ for those with $\mathrm{pDd}>1.0 \mu \mathrm{g} / \mathrm{ml}$ treated with prophylactic dose ( $\mathrm{p}<0.0001$ ), $28.8 \%$ for $\mathrm{pDd}$ for patients with $\mathrm{pDd}$ $>2.0 \mu \mathrm{g} / \mathrm{ml}$ treated with intermediate dose $(\mathrm{p}=0.0001)$, and $31.3 \%$ for those with $\mathrm{pDd}>3.0 \mu \mathrm{g} / \mathrm{ml}$ and full anticoagulation ( $\mathrm{p}=0.0183)$.

CONCLUSIONS: In hospitalized patients with COVID-19, a pDd value greater than $3.0 \mu \mathrm{g} / \mathrm{ml}$ can be considered to screen VTE and to consider full-dose anticoagulation. 
KEY WORDS: COVID-19; SARS-CoV-2; venous thrombotic event; deep vein thrombosis; pulmonary embolism; D-dimer.

$J$ Gen Intern Med 36(11):3478-86

DOI: $10.1007 / \mathrm{s} 11606-021-07017-8$

(c) Society of General Internal Medicine 2021

\section{INTRODUCTION}

Since the beginning of the novel coronavirus disease 2019 (COVID-19) outbreak, many studies have reported coagulation abnormalities and a higher incidence of venous thrombotic events (VTE) among these patients. A relationship between plasma D-dimer (pDd) $>1.0 \mu \mathrm{g} / \mathrm{ml}$ and both the severity of the infection and a worse prognosis has also been described. ${ }^{1-3}$

VTE has been detected in 3 to $46 \%$ of the patients with COVID-19, with the highest prevalence in patients in intensive care units (ICU) ${ }^{4-17}$ These rates are higher than those reported in non-COVID-19 patients $^{18-20}$ and have been related to a higher mortality. ${ }^{5}$

The diagnosis of VTE in patients with COVID-19 is challenging because its clinical manifestations and analytical findings can be misdiagnosed. The usual $\mathrm{pDd}$ cut-off value of 0.5 $\mu \mathrm{g} / \mathrm{ml}^{21,22}$ may not be useful and could lead to overdiagnosis and anticoagulation. For these reasons, some authors have tried to establish a higher pDd threshold, with different higher cut-off values. ${ }^{10,14,16,17}$ However, these studies have several limitations, including small sample sizes, a lack of validation, and heterogeneity in methodology.

The SEMI-COVID-19 Registry emerged as an initiative of the Spanish Society of Internal Medicine (SEMI, for its initials in Spanish) to improve the quality of treatment of hospitalized SARS-CoV-2-infected patients. A retrospective analysis of the data from the registry has been conducted to determine the optimal cut-off value of admission pDd to guide the diagnosis and treatment of VTE in these patients.

\section{MATERIAL AND METHODS}

\section{The SEMI-COVID-19 Registry}

The SEMI-COVID-19 Registry is an ongoing nationwide, multicenter (150 hospitals through the 17 regions of Spain), observational, retrospective cohort registry. ${ }^{23}$ All consecutive hospitalized patients aged $\geq 18$ years with confirmed SARSCoV-2 infection, according to World Health Organization (WHO) recommendations ${ }^{24}$ were eligible for inclusion. The exclusion criteria were subsequent admissions of the same patient and denial or withdrawal of informed consent. The admission and treatment of patients were at the discretion of the attending physicians. Personal data processing strictly complied with the applicable European Union and Spanish laws on biomedical research and personal data protection. The Registry has been approved by the Provincial Research Ethics
Committee of Málaga (Spain) as per the recommendation of the Spanish Agency of Medicines and Medical Products (AEMPS, for its initials in Spanish). All patients gave informed consent. The conduct and reporting of the study were carried out pursuant to the STROBE statement guidelines. ${ }^{25}$

\section{Procedures}

A specific online electronic data capture system (DCS) was developed. Physicians from each participating hospital were responsible for acquiring and entering data. To ensure the quality of data collection, a database manager and data verification procedures were designed. Data monitoring, analysis, and logistics coordination were carried out by independent external agencies. The DCS did not contain any direct patient identifiers.

A total of 321 variables were retrospectively collected. A full list of variables gathered can be found in the source paper. ${ }^{23}$ The unadjusted and age-adjusted Charlson Comorbidity Index was calculated from the collected data. ${ }^{26} \mathrm{~A}$ total of 13,403 consecutive patients were recruited from March 1 to June 4, 2020, when the last patient was included in the present substudy.

\section{Objectives}

The main objective was to establish a cut-off value of admission $\mathrm{pDd}$ associated with the development of in-hospital VTE in COVID-19 patients, to be used as a tool for ruling out this complication. As the secondary objective, a post-hoc analysis was undertaken to evaluate if anticoagulation intensity (prophylactic, intermediate, or therapeutic doses) was associated with admission $\mathrm{pDd}$ values and mortality.

\section{Statistical Analysis}

As can be seen in the patient inclusion flowchart (Fig. 1), patients without information on acute VTE during hospitalization and those without a registered at admission $\mathrm{pDd}$ value were excluded. The final sample comprised 9386 patients, and 66 variables were analyzed (Appendix 2).

Patients were divided into two groups: those with an acute VTE episode (DVT and/or PE) anytime during hospitalization, and those in which it was registered that they had not suffered a VTE episode during hospitalization. Recording of venous thrombotic events in the Registry was declarative, categorical (Yes/No), and dependent on each participant physician criteria.

Quantitative variables are expressed as medians (interquartile range) or means (SD). Categorical variables are expressed as absolute values and percentages. Categorical variables were compared using the chi-square test and quantitative variables using Student's $t$ test for variables with a normal distribution and the Mann-Whitney $U$ test for non-parametric variables. The alpha significance level was established as 0.05 , with the Bonferroni correction applied for multiple comparisons. A receiver operating characteristic (ROC) curve was generated to 


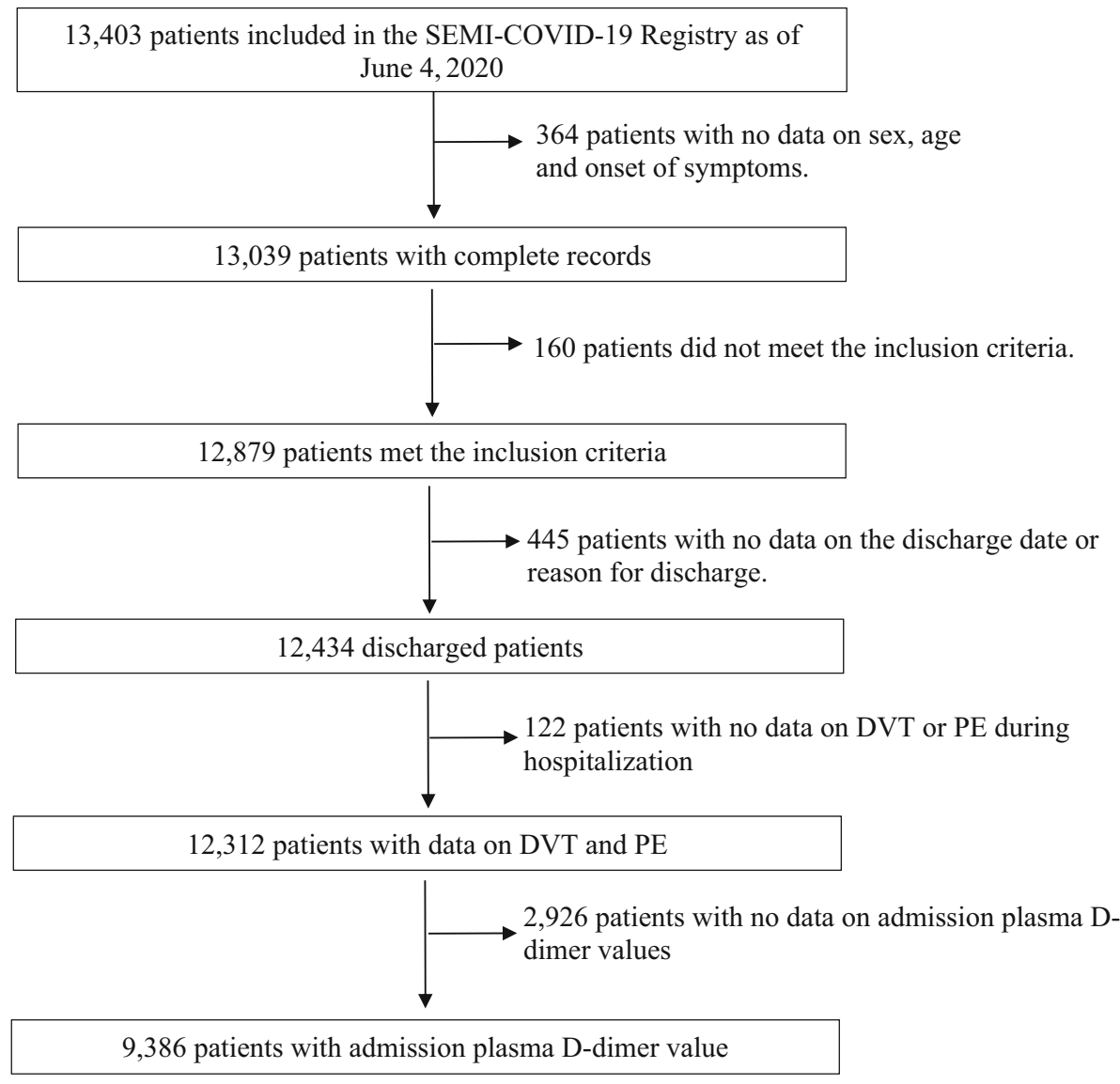

Figure 1 Flowchart for the selection of the study population. DVT, deep venous thrombosis; PE, pulmonary embolism.

determine the sensitivity, specificity, positive predictive value (PPV), and negative predictive value (NPV) of admission $\mathrm{pDd}$ values to predict acute VTE during hospitalization. The optimal pDd cut-off value was estimated based on two criteria: iteration over a range of specificity values and maximization of product of sensitivity and specificity (accuracy area).

Overall mortality in all the included patients was stratified according to $\mathrm{pDd}$ value categories, and the impact on this variable of different anticoagulation intensities was analyzed for each pDd category. Four categories of anticoagulation intensities were established: absent, low intensity, intermediate intensity, and full intensity, depending on the LMWH given during hospitalization. Definitions of LMWH dose categories are provided in Appendix 2. For patients in different pDd value categories, the overall mortality for each anticoagulation intensity was compared using the chi-square test.

All statistical analyses were performed using the R Foundation for Statistical Computing.

\section{RESULTS}

\section{Characteristics of the study population}

According to the flowchart in Figure 1, 9386 patients were included in the analysis. Of them, $57.1 \%$ were male and the median age was 68.4 (interquartile range [IQR] 55-79) years.
The prevalence of comorbidities was $16.1 \%$, as measured by the Charlson age-adjusted Comorbidity Index (Table 1).

Acute VTE during hospitalization occurred in 202 patients (2.2\%): PE alone in 151 patients (1.6\%), DVT alone in 37 patients $(0.4 \%)$, and both DVT and PE in 14 patients $(0.2 \%)$. The most frequent comorbidities in the VTE group were hypertension $(50.0 \%)$, dyslipidemia $(43.3 \%)$, diabetes mellitus (14.39\%), and cancer (10.4\%). Applying the Bonferroni correction, the significance level was established as 0.0007 , and no significant differences were found between the groups regarding baseline demographic and clinical characteristics. Patients in the VTE group had a higher prevalence of tachypnea ( $42.9 \%$ vs. $31.1 \% ; \mathrm{p}=0.0005)$ and basal oxygen saturation $<93 \%$ (45.4\% vs. $33.1 \%$; $\mathrm{p}=0.0003)$. A quick SOFA score greater than or equal to 2 points was found in $8.5 \%$ of all participants, with no significant differences between groups (Table 2).

When analytical parameters were considered (Table 3), patients with VTE had a significantly higher pDd value at admission (median [IQR]: 1.4 [0.6-5.4] $\mu \mathrm{g} / \mathrm{ml}$ vs 0.6 [0.3-1.2] $\mu \mathrm{g} / \mathrm{ml} ; \mathrm{p}<0.00001)$. VTE patients also had significantly higher neutrophil count in peripheral blood (median [IQR]: 5300 [3810-7600] cells $\times 10^{6} / \mathrm{L}$ vs 4500 [3200-6560] cells $\times 10^{6} \%$ $\mathrm{L} ; \mathrm{p}=0.0008$ ) and higher platelet counts (median [IQR]: 208 $[158-289]$ cells $\times 10^{9} / \mathrm{L}$ vs $190[148-246]$ cells $\times 10^{9} / \mathrm{L} ; \mathrm{p}=$ 0.0013 ), with no other significant differences. 
Table 1 Basal Characteristics of Included Patients

\begin{tabular}{|c|c|c|c|c|}
\hline Variable & All patients $(n=9386)$ & VTE group $(n=202)$ & Non-VTE group $(n=9184)$ & $p^{*}$ \\
\hline Age (median [IQR]), years & $66.7[55.8-79.0]$ & $69.4[59.3-77.5]$ & $68.4[55.7-77.0]$ & 0.4928 \\
\hline Male sex, $\mathrm{n}(\%)$ & $5356(57.1)$ & $121(60.2)$ & $5235(57.1)$ & 0.4152 \\
\hline $\mathrm{HBP}, \mathrm{n}(\%)$ & $4695(50)$ & $101(50.0)$ & 4594 (49.9) & 0.9999 \\
\hline DM, n (\%) & 1749 (18.6) & $29(14.4)$ & $1720(18.7)$ & 0.9637 \\
\hline Dyslipidemia, n (\%) & $3667(39.1)$ & $8(43.3)$ & $3580(39.1)$ & 0.2537 \\
\hline Alcohol abuse, n (\%) & $419(4.4)$ & $15(7.7)$ & $404(4.5)$ & 0.0575 \\
\hline Smoking, n (\%) & & & & 0.5911 \\
\hline Former smoker & $2193(23.4)$ & $51(25.9)$ & $2142(24.4)$ & \\
\hline Current smoker & $475(5)$ & $13(6.6)$ & $462(5.3)$ & \\
\hline Dependence, n (\%) & & & & 0.1964 \\
\hline Absent/mild & $7802(83.1)$ & $175(87.9)$ & $7627(84.0)$ & \\
\hline Moderate & $846(9.0)$ & $11(5.5)$ & $835(9.2)$ & \\
\hline Severe & $631(6.7)$ & $13(6.5)$ & $618(6.8)$ & \\
\hline Atrial fibrillation, n (\%) & $984(10.5)$ & $9(4.5)$ & $975(10.6)$ & 0.0064 \\
\hline Chronic anxiety, n (\%) & $753(8)$ & $20(9.9)$ & $733(8.0)$ & 0.3941 \\
\hline Chronic depression, n (\%) & $981(10.5)$ & $29(14.4)$ & $952(10.4)$ & 0.0879 \\
\hline Obesity, n (\%) & $1795(19.0)$ & $49(25.8)$ & $1746(20.7)$ & 0.1065 \\
\hline Neurodegenerative disease, $\mathrm{n}(\%)$ & $801(8.5)$ & $13(6.5)$ & $788(8.6)$ & 0.3479 \\
\hline Angina, n (\%) & $321(3.4)$ & $6(3.0)$ & $315(3.4)$ & 0.8701 \\
\hline $\mathrm{CHF}, \mathrm{n}(\%)$ & $615(6.5)$ & $11(5.5)$ & $604(6.6)$ & 0.6135 \\
\hline COPD, n (\%) & $599(6.3)$ & $10(5.0)$ & $589(6.4)$ & 0.4831 \\
\hline Asthma, n (\%) & $720(7.6)$ & $13(6.5)$ & $410(7.7)$ & 0.6014 \\
\hline TIA, n $(\%)$ & $420(4.4)$ & $10(5.0)$ & $410(4.5)$ & 0.8796 \\
\hline Previous IS, n (\%) & $246(2.6)$ & $7(3.5)$ & $239(2.6)$ & 0.5941 \\
\hline Residual hemiplegia, n (\%) & $151(1.6)$ & $4(2.0)$ & $147(1.6)$ & 0.8819 \\
\hline Dementia, n (\%) & $893(9.5)$ & $17(8.4)$ & $876(9.6)$ & 0.6703 \\
\hline PVD, n (\%) & $413(4.4)$ & $11(5.5)$ & $402(4.4)$ & 0.5826 \\
\hline CLD, n (\%) & $253(0.2)$ & $245(2.6)$ & $8(3.9)$ & 0.3709 \\
\hline CKD, n (\%) & $545(5.8)$ & $11(5.5)$ & $534(5.8)$ & 0.9372 \\
\hline Active cancer, n (\%) & $532(5.6)$ & $21(10.4)$ & $511(5.6)$ & 0.0054 \\
\hline CTD, n (\%) & $225(2.3)$ & $7(3.5)$ & $218(2.4)$ & 0.4375 \\
\hline HIV infection, n (\%) & $63(0.6)$ & $0(0)$ & $63(0.7)$ & 0.9999 \\
\hline OSAS, n (\%) & $575(6.1)$ & $15(7.5)$ & $560(6.1)$ & 0.5313 \\
\hline CCI, Med. (IQR) & $1[0-2]$ & $1[0-2]$ & $1[0-2]$ & 0.4388 \\
\hline $\mathrm{CCI} \geq 3, \mathrm{n}(\%)$ & $1515(16.1)$ & $36(18.2)$ & $1479(16.5)$ & 0.5814 \\
\hline
\end{tabular}

VTE, venous thromboembolism; HBP, chronic high blood pressure; DM, diabetes mellitus; CHF, chronic heart failure; COPD, chronic obstructive pulmonary disease; TIA, transient ischemic accident; IS, ischemic stroke; PVD, peripheral vascular disease; CLD, chronic liver disease; CKD, chronic kidney disease; CTD, connective tissue disease; HIV, human immunodeficiency virus; OSAS, obstructive sleep apnea syndrome; CCI, age-adjusted Charlson Comorbidity Index; Med, median; IQR, interquartile range

*Comparison of VTE vs. non-VTE groups

\section{Admission Plasma D-dimer Cut-off Value and Incidence of VTE}

Different $p D d$ cut-off values were analyzed for their sensitivity, specificity, PPV, and NPV for the diagnosis of VTE. For the maximum accuracy area, a cut-off value of $1.1 \mu \mathrm{g} / \mathrm{ml}$ showed a specificity of $72 \%$, sensitivity of $49 \%$, PPV of $4 \%$, and NPV of $99 \%$. This value had an area under the ROC curve of 0.7 (95\% CI: 0.66-0.74) (Fig. 2). Otherwise, iterating through the different specificity values (Table 4 ), a specificity of $95 \%$ was obtained with a cut-off value of $4.7 \mu \mathrm{g} / \mathrm{ml}$, with a sensitivity of $27 \%$, PPV of $9 \%$, and NPV of $98 \%$.

\section{Admission Plasma D-dimer Value, Overall Mortality, and Anticoagulation Intensity}

Table 5 shows the analysis of different anticoagulation intensity regimens with different doses of LMWH and other anticoagulant drugs along with overall mortality stratified by $\mathrm{pDd}$ in all the cohort patients. Overall mortality was present in $17.6 \%$ of all the cases. In the absence of anticoagulation, mortality was found to increase as pDd values increased, with an overall mortality of $19.2 \%$, and percentages ranging from
42.3 to $54.1 \%$ for pDd values higher than $1.0 \mu \mathrm{g} / \mathrm{mL}$ and 5.0 $\mu \mathrm{g} / \mathrm{mL}$, respectively. A proportional relationship between increasing mortality and increasing pDd values was also found in patients in all anticoagulation intensity groups. In each pDd level, mortality was affected by the intensity of the anticoagulant strategy. As showed in Table 5, the lowest mortality was found in patients with $\mathrm{pDd}>1.0 \mu \mathrm{g} / \mathrm{mL}$ treated with prophylactic doses of LMWH (26.3\%; $p<0.0001$ for the absent, low, intermediate, and full anticoagulation comparison), those with $\mathrm{pDd}>2.0 \mu \mathrm{g} / \mathrm{ml}$ treated with intermediate LMWH doses $(28.8 \% ; \mathrm{p}=0.0001)$, and those with $\mathrm{pDd}>3.0 \mu \mathrm{g} / \mathrm{ml}$ treated with full anticoagulation with LMWH or other drugs (31.3\%; $\mathrm{p}=0.0183$ ).

\section{DISCUSSION}

In our work, the overall prevalence of VTE was $2.2 \%$, lower than previously described, ${ }^{4-10,12-15}$ even for patients admitted to conventional hospital wards without active radiological screening for VTE. ${ }^{5,6,8,12,15}$ In non-critical hospitalized patients, the reported rates are $3.3 \%$ and $6.6 \%,{ }^{5,12}$ lower than those in studies 
Table 2 COVID-19-Related Clinical Variables of Included Patients

\begin{tabular}{|c|c|c|c|c|}
\hline$\overline{\text { Variable }}$ & All patients $(\mathrm{n}=9386)$ & VTE group $(n=202)$ & Non-VTE group $(n=9184)$ & $\mathbf{p}^{*}$ \\
\hline Cough, n (\%) & & & & 0.8839 \\
\hline Dry & $5595(59.6)$ & $122(60.7)$ & $5473(59.8)$ & \\
\hline Wet & $1342(14.3)$ & $30(14.9)$ & $1312(14.3)$ & \\
\hline Myalgia, n (\%) & $2858(30.4)$ & $54(27.1)$ & $2804(30.8)$ & 0.3032 \\
\hline Ageusia, n (\%) & $703(7.4)$ & $17(8.7)$ & $686(7.6)$ & 0.6555 \\
\hline Anosmia, n (\%) & $613(6.5)$ & $14(7.2)$ & $599(6.7)$ & 0.8766 \\
\hline Asthenia, n (\%) & 4085 (43.5) & $85(42.9)$ & $4000(44.0)$ & 0.8230 \\
\hline Anorexia, n (\%) & $1788(19.0)$ & $35(17.7)$ & $1753(19.4)$ & 0.6150 \\
\hline Odynophagia, n (\%) & $900(9.6)$ & $20(10.2)$ & $880(9.7)$ & 0.9259 \\
\hline Headache, n $(\%)$ & $1054(11.2)$ & $20(10.2)$ & 1034 (11.4) & 0.6697 \\
\hline Dyspnea, $\mathrm{n}(\%)$ & $5446(58.0)$ & $133(66.2)$ & $5313(58.1)$ & 0.0260 \\
\hline Diarrhea, n (\%) & $2275(24.2)$ & $42(21.1)$ & $2233(24.5)$ & 0.3112 \\
\hline Nausea, n (\%) & $1125(12.0)$ & $26(13.1)$ & $1099(12.1)$ & 0.7574 \\
\hline Vomiting, n (\%) & $678(7.2)$ & $11(5.5)$ & $667(7.3)$ & 0.4102 \\
\hline Abdominal pain, n (\%) & $592(6.3)$ & $13(6.6)$ & $579(6.4)$ & 0.9999 \\
\hline Confusion, n (\%) & $1023(10.9)$ & $24(12.0)$ & $999(11.0)$ & 0.7335 \\
\hline Tachypnea, n (\%) & $2874(30.6)$ & $84(42.9)$ & $2790(31.1)$ & 0.0005 \\
\hline $\mathrm{SBP}, \mathrm{mmHg}($ mean $\pm \mathrm{SD})$ & $128.5 \pm 20.1$ & $129 \pm 20.3$ & $129 \pm 21.1$ & 0.9337 \\
\hline $\mathrm{DBP}, \mathrm{mmHg}($ mean $\pm \mathrm{SD})$ & $73.9 \pm 12.9$ & $75 \pm 13$ & $74 \pm 12.9$ & 0.2856 \\
\hline Heart rate, bpm $($ mean \pm SD) & $88.4 \pm 17.4$ & $92.5 \pm 18.1$ & $88.4 \pm 17.3$ & 0.0023 \\
\hline Temperature, ${ }^{\circ} \mathrm{C}($ mean $\pm \mathrm{SD})$ & $37.05 \pm 0.97$ & $37.1 \pm 1.0$ & $37.1 \pm 1.0$ & 0.2218 \\
\hline Temperature $\geq 38^{\circ} \mathrm{C}, \mathrm{n}(\%)$ & $5996(63.9)$ & $41(20.6)$ & $1955(21.4)$ & 0.2615 \\
\hline Crackles, n (\%) & $4989(53.2)$ & $108(54.8)$ & $4881(54.2)$ & 0.9201 \\
\hline Wheezing, n (\%) & $549(5.85)$ & $10(5.1)$ & $539(6.0)$ & 0.7023 \\
\hline Rhonchi, n (\%) & $954(10.2)$ & $21(10.7)$ & $933(10.4)$ & 0.9894 \\
\hline Basal O2 sat, \% (mean $\pm \mathrm{SD})$ & $93.06 \pm 5.7$ & $91.2 \pm 7.1$ & $93.1 \pm 5.7$ & 0.0003 \\
\hline Basal O2 sat $<93 \%$, n (\%) & $3053(32.5)$ & $89(45.4)$ & $2964(33.0)$ & 0.0003 \\
\hline qSOFA $>2, \mathrm{n}(\%)$ & $799(8.5)$ & $23(11.3)$ & $776(8.4)$ & 0.1764 \\
\hline
\end{tabular}

SBP, systolic blood pressure; DBP, diastolic blood pressure; bpm, beats per minute; qSOFA, quick sequential organ failure assessment scale; SD, standard deviation

*Comparison of VTE vs. non-VTE groups

Table 3 Blood Count and Coagulation Parameters of Included Patients

\begin{tabular}{|c|c|c|c|c|}
\hline$\overline{\text { Variable }}$ & All patients $(\mathrm{n}=9386)$ & VTE group $(n=202)$ & Non-VTE group $(n=9184)$ & $\mathbf{p}^{*}$ \\
\hline $\begin{array}{l}\text { Lymphocytes } \times 10^{6} / \mathrm{L}(\mathrm{Med} .[\mathrm{IQR}]) \\
\text { Neutrophils } \times 10^{6} / \mathrm{L}(\mathrm{Med} .[\mathrm{IQR}]) \\
\text { Platelets } \times 10^{9} / \mathrm{L}(\mathrm{Med} \text {. [IQR]) } \\
\text { Prothrombin time (Med. [IQR]) } \\
\text { D-dimer, } \mu \mathrm{g} / \mathrm{ml}(\text { Med. [IQR]) }\end{array}$ & $\begin{array}{l}950[750-1300] \\
4520[3200-6600] \\
190[148-246] \\
12.9[11.9-14.2] \\
0.64[0.36-1.2]\end{array}$ & $\begin{array}{l}900[620-1800] \\
5300[3810-7600] \\
208[158-289] \\
12.7[11.6-14] \\
1.41[0.61-5.46]\end{array}$ & $\begin{array}{l}950[700-1300] \\
4500[3200-6560] \\
189[148-245] \\
12.9[11.9-14.2] \\
0.63[0.36-1.17]\end{array}$ & $\begin{array}{l}0.0594 \\
0.0008 \\
0.0013 \\
0.0604 \\
<0.0001\end{array}$ \\
\hline
\end{tabular}

Med., median; IQR, interquartile range

*Comparison of VTE vs. non-VTE groups

on patients in the ICU, with a prevalence between 16.7 and $28 \%{ }^{5,6,8,12,15}$ In studies in which asymptomatic patients were screened for DVT, the proportion ranges from $14.7 \%$ in a conventional ward, ${ }^{10} 46.1 \%$ in a study with ICU and non-ICU patients, ${ }^{13}$ and $69 \%$ in ICU patients. ${ }^{4}$ In a non-ICU group that

Table 4 Plasma D-dimer Values Initially Analyzed for Cut-off and Their Sensitivity, Specificity, and Predictive Values for the Diagnosis of VTE

\begin{tabular}{lllll}
\hline \hline $\begin{array}{l}\text { Plasma D-dimer Value } \\
(\boldsymbol{\mu} \mathbf{g} / \mathbf{m l})\end{array}$ & Sensitivity & Specificity & NPV & PPV \\
\hline 0.79 & 0.69 & 0.60 & 0.99 & 0.04 \\
1.03 & 0.59 & 0.70 & 0.99 & 0.04 \\
1.44 & 0.50 & 0.80 & 0.98 & 0.05 \\
2.45 & 0.39 & 0.90 & 0.98 & 0.08 \\
4.69 & 0.27 & 0.95 & 0.98 & 0.11 \\
\hline
\end{tabular}

$N P V$, negative predictive value; $P P V$, positive predictive value underwent a computed tomography pulmonary angiogram, 23\% had PE. ${ }^{7}$ These rates are higher than those previously reported in non-COVID-19 patients, with a global prevalence of about $16 \%$ in conventional wards and 4.8 to $31.0 \%$ in ICUs. ${ }^{18-20}$ The huge differences in reported prevalence are secondary to the different considered scenarios (ICU vs non-ICU patients) and the use of active radiological screening.

The classical risk factors for VTE are common in COVID19 patients. However, these factors do not seem to fully explain the higher frequency of thrombotic complications observed. According to this observation, in the present study, no significant differences were found in the prevalence of these classical prothrombotic factors when comparing patients with and without VTE. On the other hand, SARS-CoV-2 itself is able to induce a prothrombotic state related to an inflammatory reaction, ${ }^{27-29}$ as has been demonstrated in autopsy 


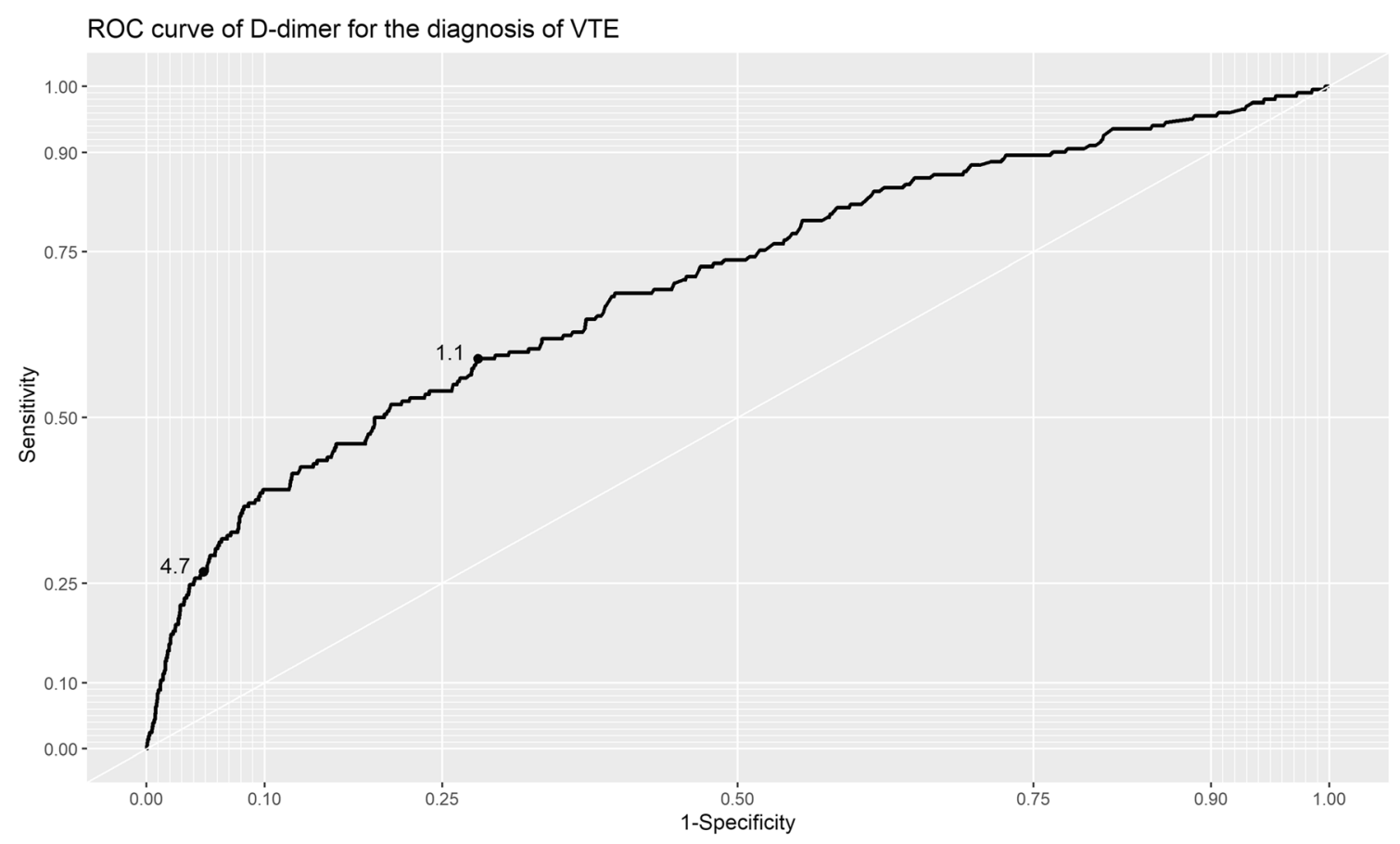

Figure 2 ROC curve of at admission pDd values $(\mu \mathrm{g} / \mathrm{ml})$ and incidence of VTE during hospitalization.

studies, with frequent local pulmonary microthrombosis and endotheliitis $^{30-33}$ and evidences about complement activation. ${ }^{34}$ Related to these observations, in a recent prospective observational study on 26 COVID-19 hospitalized patients who developed PE, DVT was only detected in $7.7 \%$ (95\% CI: $3.6-11.7 \%$ ) of the cases after systematic screening with compression ultrasound. ${ }^{9}$ This points to the possibility that local lung inflammation and pulmonary microthrombosis are especially prominent in COVID-19. ${ }^{11}$ Similar findings have been observed in our study, with a higher proportion of patients with PE alone (1.4\%) than DVT alone $(0.4 \%)$ or in combination $(0.2 \%)$. These data suggest that the use of tests specifically for detecting DVT is not sufficient for detecting VTE in COVID-19.

$\mathrm{PE}$ and SARS-CoV-2 pneumonia have similar clinical manifestations, making the diagnosis of VTE challenging in this scenario. In the general population, pDd has a high sensitivity for VTE and a very high NPV, with a cut-off value of 0.5 $\mu \mathrm{g} / \mathrm{ml}$ or age-adjusted ${ }^{22}$ for ruling out a VTE diagnosis in the case of low or intermediate pre-test probability. ${ }^{21}$ Given that patients with COVID-19 usually have high pDd values because of the infection itself, a lesser specificity can be expected, so it is necessary to search for a higher cut-off value. Different proposals of higher cut-off values have been published. In a prospective study on 156 non-ICU hospitalized COVID-19 patients, Demelo-Rodríguez et al. ${ }^{10}$ found that $14.7 \%$ of patients had DVT after the systematic screening with Doppler ultrasound, and they proposed a ROC curve cut-off value of $1.5 \mu \mathrm{g} / \mathrm{ml}$ for diagnosis. In an observational study with 106 patients, Leonard-Lorant et al. ${ }^{16}$ found that $30 \%$ had $\mathrm{PE}$ after a computerized tomography pulmonary angiogram, and established that a pDd value $>2.7 \mu \mathrm{g} / \mathrm{ml}$ detected all the cases. Cui et al. ${ }^{17}$ included 81 patients with SARS-CoV-2associated pneumonia and ICU admission and reported an

Table 5 Overall Mortality for Each Category of at Admission pDd Range and Intensity of the Applied Anticoagulation During Hospitalization in All the Studied Population

\begin{tabular}{|c|c|c|c|c|c|}
\hline \multirow[t]{2}{*}{$\overline{\overline{p D d}(\mu \mathrm{g} / \mathrm{mL})}$} & \multirow[t]{2}{*}{ No anticoagulation } & \multicolumn{3}{|c|}{ Anticoagulation intensity } & \multirow[t]{2}{*}{$p^{*}$} \\
\hline & & Low & Intermediate & Full & \\
\hline $\begin{array}{l}\text { All values } \\
>1.0 \\
>2.0 \\
>3.0 \\
>4.0 \\
>5.0\end{array}$ & $\begin{array}{l}234(19.2 \%) \\
143(42.3 \%) \\
71(51.0 \%) \\
42(50.6 \%) \\
36(52.1 \%) \\
26(54.1 \%)\end{array}$ & $\begin{array}{l}961(14.6 \%) \\
476(26.3 \%) \\
243(32.6 \%) \\
155(33.2 \%) \\
110(32.5 \%) \\
80(33.8 \%)\end{array}$ & $\begin{array}{l}123(20.9 \%) \\
67(27.8 \%) \\
36(28.8 \%) \\
27(34.2 \%) \\
24(35.2 \%) \\
21(42.0 \%)\end{array}$ & $\begin{array}{l}355(28.6 \%) \\
166(35.0 \%) \\
79(33.7 \%) \\
61(31.3 \%) \\
44(31.2 \%) \\
32(28.5 \%)\end{array}$ & $\begin{array}{l}<0.0001 \\
<0.0001 \\
0.0001 \\
0.0183 \\
0.0131 \\
0.0127\end{array}$ \\
\hline
\end{tabular}

For each pDd category overall mortality is expressed as the absolute number of deaths ( $n$ ) and percentage referred to all the patients in the considered $p D d$ range (\%). The lowest mortality group for each range of $p D d$ is marked in grey

$p D d$, plasmatic D-dimer value

*Comparison among the four anticoagulation intensity groups 
incidence of DVT of $25 \%$. Using random pDd values to establish the best cut-off value without a ROC analysis, they proposed a pDd cut-off of $1.5 \mu \mathrm{g} / \mathrm{mL}$ for the diagnosis of PE, with an estimated specificity, sensitivity, and NPV of $88.5 \%$, $85.0 \%$, and $94.7 \%$ respectively. In our patients, we found that a cut-off value of $1.1 \mu \mathrm{g} / \mathrm{mL}$ had a specificity of $72 \%$, sensitivity of $49 \%$, PPV of $4 \%$, and NPV of $99 \%$ with the maximum ROC curve accuracy area. Alternatively, a cut-off value of $4.7 \mu \mathrm{g} / \mathrm{mL}$ had $95 \%, 27 \%, 11 \%$, and $98 \%$ respectively, improving the specificity and consequently the PPV while maintaining a very high NPV. These higher cut-offs may be helpful for screening and ruling out VTE in patients with low and intermediate pretest probability, while in patients with higher pDd, a radiological test, such as a Doppler ultrasound or a multidetector computed tomography pulmonary angiogram, should be performed, to confirm the diagnosis of DVT or PE.

Because the range of $\mathrm{pDd}$ values found in our study was quite broad, we attempted to determine a value with potential clinical significance. To do so, we performed a stratified analysis, correlating at admission pDd value range and mortality, finding higher mortality with higher pDd values. We also found that initial anticoagulation intensity modified overall in-hospital mortality with the higher benefit with the higher dose in patients in the higher $\mathrm{pDd}$ range. For patients with $\mathrm{pDd}$ $>3.0 \mu \mathrm{g} / \mathrm{mL}$, the group which received full anticoagulation had lower mortality than groups which received less intensive anticoagulation. It should also be underscored that patients with pDd levels between 2.0 and $3.0 \mu \mathrm{g} / \mathrm{mL}$ had better outcomes with intermediate doses of LMWH and those with $\mathrm{pDd}$ $<2.0 \mu \mathrm{g} / \mathrm{mL}$ had lower mortality with prophylactic doses of LMWH. Of note, prophylactic anticoagulation was related to a lower overall mortality rate in all patients and across all $\mathrm{pDd}$ values, with an overall mortality of $19.2 \%$ in patients without anticoagulation and $14.6 \%$ in those with LMWH at prophylactic doses, as seen in a previous study. ${ }^{35}$

Most experts recommend prophylactic LMWH for all COVID-19 patients. ${ }^{36}$ However, full anticoagulation is usually not recommended because of a lack of evidence on the clinical benefits and the potential risk of complications. ${ }^{28,37,38}$ Despite the current uncertainty, ${ }^{39}$ our findings about the use of different anticoagulation intensities according to $\mathrm{pDd}$ are in accordance with Maatman et al., ${ }^{40}$ who reported that the use of prophylactic doses of LMWH failed to prevent VTE in 26.6\% of patients in the ICU, and that a pDd value $>3.0 \mu \mathrm{g} / \mathrm{mL}$ was a predictor of this failure. In this line, a recent study on VTE diagnosis by ultrasound in COVID-19 patients admitted to the $\mathrm{ICU}^{14}$ recommends ultrasound evaluation when $\mathrm{pDd}>2.0 \mu \mathrm{g} /$ $\mathrm{mL}$ (sensitivity $95 \%$, specificity $46 \%$ ) and full empiric anticoagulation to be considered when $\mathrm{pDd}>5.5 \mu \mathrm{g} / \mathrm{mL}$ (sensitivity $53 \%$, specificity $88 \%$ ). Compared to this proposal, in our study, a pDd threshold of $3.0 \mu \mathrm{g} / \mathrm{mL}$ showed higher specificity (about 90\%) and slightly less sensitivity (about $40 \%)$. Unfortunately, bleeding events or bleeding-related deaths were not captured in the Registry, although the stratified analysis suggests that this strategy is beneficial as overall mortality is reduced. Nevertheless, there is a lack of unanimity among different guidelines, especially in terms of determining anticoagulation intensity ${ }^{36}$ and the finding in our study is merely exploratory.

Among limitations of the present study, it has to be considered those related with the kind of study, an observational, retrospective one in which data were collected by a large team of different researchers, which could have led to heterogeneity in data entry and validation mainly because of the declarative character of the registry. Consequently, the diagnostic criteria have not been uniform. Moreover, since data has been obtained from a multicenter registry in which the incidence of VTE has been declarative according to each investigator criteria, some asymptomatic VTE patients may have erroneously been included in the non-VTE group. This last point could explain the low prevalence of thrombotic events in our cohort falsely decreasing the pre-test probability. Therefore, the PPV tends to be low and the NPV tends to be high, regardless of sensitivity and specificity. It has also to be considered that the specific causes of death were not registered, so analysis by confounding factors could not be done in the analysis of mortality and anticoagulation intensity stratified by pDd levels. It has also to be recognized as a limitation of the study that, although the suggested benefit on overall mortality depending on each admission pDd value category and the anticoagulation intensity, hemorrhagic events were not registered, and their analysis could have helped to estimate the net benefit of the suggested anticoagulation strategies. When considering the strengths of the study, it has to be underscored that, to date, it has the largest number of participants in real-world clinical practice and spans the entire geographical area of the same healthcare system, and the conclusions have been drawn from daily clinical activity and suggestions can be used in a real-world setting.

In conclusion, to improve the specificity of $\mathrm{pDd}$ as a predictor of VTE in COVID-19 patients, cut-off values $>1 \mu \mathrm{g} / \mathrm{ml}$ $\mathrm{pDd}$ should be used. Our data also suggest that pDd $>3 \mu \mathrm{g} / \mathrm{ml}$ improves specificity and PPV while maintaining a high NPV in this population. These thresholds can be useful for the screening of VTE in COVID-19 patients and can also be used as a help for the clinician to determine if radiological confirmation is necessary, and probably to initiate full-dose anticoagulation. Finally, our results suggest that prophylactic LMWH should be applied to all hospitalized patients with COVID-19, and also that pDd values could help to decide the anticoagulation intensity to be used at admission in hospitalized patients with COVID-19.

As the evidence has been obtained from a retrospective observational study, the suggestions made based on this work should be further studied in randomized prospective studies, though given the current lack of evidence, the results of this study can be considered helpful in daily clinical practice. 
Supplementary Information The online version contains supplementary material available at https://doi.org/10.1007/s11606-021-07017-8.

Acknowledgements: A complete list of the SEMI-COVID-19 Network members is provided in the Appendix 1. We gratefully acknowledge all the investigators who participate in the SEMI-COVID-19 Registry. We also thank the SEMI-COVID-19 Registry Coordinating Center, S\&H Medical Science Service, for their quality control data, logistic and administrative support.

Corresponding Author: Philip Wikman-Jorgensen, $M D$, PhD; General Internal Medicine Department, Hospital Universitario San Juan de Alicante, San Juan de Alicante, Alicante, Spain (e-mail: wikman. philip@gmail.com).

Funding The Spanish Society of Internal Medicine (SEMI) is the sponsor of this study. This research has not received specific aid from public sector agencies, commercial sector, or non-profit entities.

\section{Declarations:}

Conflict of Interest: The authors declare no conflicts of interest.

\section{REFERENCES}

1. Zhou F, Yu T, Du R, et al. Clinical course and risk factors for mortality of adult inpatients with COVID-19 in Wuhan, China: a retrospective cohort study. Lancet. 2020;395(10229):1054-1062. https://doi.org/10.1016/ S0140-6736(20)30566-3

2. Onder G, Rezza G, Brusaferro S. Case-fatality rate and characteristics of patients dying in relation to COVID-19 in Italy. JAMA. 2020;323(18):1775-1776. https://doi.org/10.1001/jama.2020.4683

3. Wu C, Chen X, Cai Y, et al. Risk factors associated with acute respiratory distress syndrome and death in patients with coronavirus disease 2019 pneumonia in Wuhan, China. JAMA Intern Med. 2020;180(7):934-943. https://doi.org/10.1001/jamainternmed.2020.0994

4. Llitjos, J-F, Leclerc, M, Chochois, C, et al. High incidence of venous thromboembolic events in anticoagulated severe COVID-19 patients. J Thromb Haemost. 2020; 18: 1743- 1746. https://doi.org/10.1111/jth. 14869

5. Middeldorp S, Coppens M, van Haaps TF, et al. Incidence of venous thromboembolism in hospitalized patients with COVID-19. J Thromb Haemost. 2020;18(8):1995-2002. https://doi.org/10.1111/jth. 14888

6. Klok FA, Kruip MJHA, van der Meer NJM, et al. Incidence of thrombotic complications in critically ill ICU patients with COVID-19. Thromb Res. 2020;191:145-147. https://doi.org/10.1016/j.thromres. 2020.04.013

7. Grillet F, Behr J, Calame P, Aubry S, Delabrousse E. Acute pulmonary embolism associated with COVID-19 pneumonia detected with pulmonary CT angiography. Radiology. 2020;296(3):E186-E188. https://doi. org/10.1148/radiol.2020201544

8. Poissy J, Goutay J, Caplan M, et al. Pulmonary Embolism in Patients With COVID-19: Awareness of an Increased Prevalence. Circulation. 2020;142(2):184-186. https://doi.org/10.1161/CIRCULATIONAHA. 120. 047430

9. Franco-Moreno A, Herrera-Morueco M, Mestre-Gómez B, et al. Incidence of deep venous thrombosis in patients with COVID-19 and pulmonary embolism: Compression Ultrasound COVID Study [published online ahead of print, 2020 Oct 5]. J Ultrasound Med. 2020. https://doi. org/10.1002/jum. 15524

10. Demelo-Rodriguez $\mathbf{P}$, Cervilla-Muñoz E, Ordieres-Ortega $\mathbf{L}$, et al. Incidence of asymptomatic deep vein thrombosis in patients with COVID-19 pneumonia and elevated D-dimer levels. Thromb Res. 2020; 192:23-26. https://doi.org/10.1016/j.thromres.2020.05.018

11. Franco-Moreno A, Muñoz-Rivas N, Mestre-Gómez B, Torres-Macho J. Pulmonary embolism and COVID-19: a paradigm change. Tromboembolismo pulmonar y COVID-19: un cambio de paradigma. Rev Clin Esp. 2020;220(7):459-461. https://doi.org/10.1016/j.rce.2020. 05.006
12. Lodigiani C, Iapichino G, Carenzo L, et al. Venous and arterial thromboembolic complications in COVID-19 patients admitted to an academic hospital in Milan, Italy. Thromb Res. 2020;191:9-14. https:// doi.org/10.1016/j.thromres.2020.04.024

13. Zhang $\mathbf{L}$, Feng $\mathbf{X}$, Zhang $\mathbf{D}$, et al. Deep Vein Thrombosis in Hospitalized Patients With COVID-19 in Wuhan, China: Prevalence, Risk Factors, and Outcome. Circulation. 2020;142(2):114-128. https://doi.org/10.1161/ CIRCULATIONAHA. 120.046702

14. Trigonis RA, Holt DB, Yuan R, et al. Incidence of Venous Thromboembolism in Critically Ill Coronavirus Disease 2019 Patients Receiving Prophylactic Anticoagulation. Crit Care Med. 2020;48(9):e805-e808. https://doi.org/10.1097/CCM.0000000000004472

15. Helms J, Tacquard C, Severac F, et al. High risk of thrombosis in patients with severe SARS-CoV-2 infection: a multicenter prospective cohort study. Intensive Care Med. 2020;46(6):1089-1098. https://doi. org/10.1007/s00134-020-06062-x

16. Léonard-Lorant I, Delabranche X, Séverac F, et al. Acute pulmonary embolism in patients with COVID-19 at CT angiography and relationship to D-dimer levels. Radiology. 2020;296(3):E189-E191. https://doi.org/ 10.1148/radiol.2020201561

17. Cui S, Chen S, Li X, Liu S, Wang F. Prevalence of venous thromboembolism in patients with severe novel coronavirus pneumonia. J Thromb Haemost. 2020; 18(6):1421-1424. https://doi.org/10.1111/jth. 14830

18. Nicholson M, Chan N, Bhagirath V, Ginsberg J. Prevention of venous thromboembolism in 2020 and beyond. J Clin Med. 2020;9(8):2467. https://doi.org/10.3390/jcm9082467

19. Malato A, Dentali F, Siragusa S, et al. The impact of deep vein thrombosis in critically ill patients: a meta-analysis of major clinical outcomes. Blood Transfus. 2015;13(4):559-568. https://doi.org/10. 2450/2015.0277-14

20. Ciuti G, Grifoni E, Pavellini A, et al. Incidence and characteristics of asymptomatic distal deep vein thrombosis unexpectedly found at admission in an internal medicine setting. Thromb Res. 2012;130(4):591-595. https://doi.org/10.1016/j.thromres.2012.05.018

21. Konstantinides SV, Meyer G, Becattini C, et al. 2019 ESC Guidelines for the diagnosis and management of acute pulmonary embolism developed in collaboration with the European Respiratory Society (ERS). Eur Heart J. 2020;41(4):543-603. https://doi.org/10.1093/eurheartj/ ehz405

22. Righini M, Van Es J, Den Exter PL, et al. Age-adjusted D-dimer cutoff levels to rule out pulmonary embolism: The ADJUST-PE Study. JAMA 2014;311(11):1117-1124. https://doi.org/10.1001/jama.2014.2135

23. Casas-Rojo JM, Antón-Santos JM, Millán-Núñez-Cortés J, et al. Clinical characteristics of patients hospitalized with COVID-19 in Spain: results from the SEMI-COVID-19 Registry. Caracteristicas clínicas de los pacientes hospitalizados con COVID-19 en España: resultados del Registro SEMI-COVID-19. Rev Clin Esp. 2020;220(8):480-494. https:// doi.org/10.1016/j.rce.2020.07.003

24. World Health Organization. Laboratory testing for coronavirus disease 2019 (COVID-19) in suspected human cases. 2020;(March): 1-7. https:// www.who.int/publications/i/item/laboratory-testing-for-2019-novel-coronavirus-in-suspected-human-cases-20200117. Accessed 29 Jun 2020

25. von Elm E, Altman DG, Egger M, Pocock SJ, Gøtzsche PC, Vandenbroucke JP. The Strengthening the Reporting of Observational Studies in Epidemiology (STROBE) statement: guidelines for reporting observational studies. J Clin Epidemiol. 2008;61(4):344-349. https:// doi.org/10.1016/j.jclinepi.2007.11.008

26. Charlson M, Szatrowski TP, Peterson J, Gold J. Validation of a combined comorbidity index. J Clin Epidemiol. 1994;47(11):1245-1251. https://doi.org/10.1016/0895-4356(94)90129-5

27. Henry BM, Vikse J, Benoit S, Favaloro EJ, Lippi G. Hyperinflammation and derangement of renin-angiotensin-aldosterone system in COVID-19: a novel hypothesis for clinically suspected hypercoagulopathy and microvascular immunothrombosis. Clin Chim Acta. 2020;507:167-173. https://doi.org/10.1016/j.cca.2020.04.027.

28. Sardu C, Gambardella J, Morelli MB, Wang X, Marfella R, Santulli G. Hypertension, thrombosis, kidney failure, and diabetes: is COVID-19 an endothelial disease? A Comprehensive Evaluation of Clinical and Basic Evidence. J Clin Med. 2020;9(5):1417. https://doi.org/10.3390/ jcm9051417

29. Connors JM, Levy JH. COVID-19 and its implications for thrombosis and anticoagulation. Blood. 2020;135(23):2033-2040. https://doi.org/ 10.1182/blood.2020006000

30. Lax SF, Skok K, Zechner P, et al. Pulmonary Arterial Thrombosis in COVID-19 With Fatal Outcome : Results From a Prospective, Single- 
Center, Clinicopathologic Case Series, Ann Intern Med. 2020;173(5):350361. https://doi.org/10.7326/M20-2566

31. Dolhnikoff M, Duarte-Neto AN, de Almeida Monteiro RA, et al Pathological evidence of pulmonary thrombotic phenomena in severe COVID-19. J Thromb Haemost. 2020;18(6):1517-1519. https://doi.org/ $10.1111 /$ jth. 14844

32. Varga Z, Flammer AJ, Steiger $\mathbf{P}$, et al. Endothelial cell infection and endotheliitis in COVID-19. Lancet. 2020;395(10234):1417-1418. https://doi.org/10.1016/S0140-6736(20)30937-5

33. Magro C, Mulvey JJ, Berlin D, et al. Complement associated microvascular injury and thrombosis in the pathogenesis of severe COVID-19 infection: a report of five cases. Transl Res. 2020;220:1-13. https://doi. org/10.1016/j.trsl.2020.04.007

34. Wang X, Sahu KK, Cerny J. Coagulopathy, endothelial dysfunction, thrombotic microangiopathy and complement activation: potential role of complement system inhibition in COVID-19 [published online ahead of print, 2020 Oct 15]. J Thromb Thrombolysis. 2020;1-6. https://doi.org/ $10.1007 / \mathrm{s} 11239-020-02297-\mathrm{Z}$

35. Tang N, Bai H, Chen X, Gong J, Li D, Sun Z. Anticoagulant treatment is associated with decreased mortality in severe coronavirus disease 2019 patients with coagulopathy. J Thromb Haemost. 2020;18(5): 1094-1099. https://doi.org/10.1111/jth.14817

36. Flaczyk A, Rosovsky RP, Reed CT, Bankhead-Kendall BK, Bittner EA,

Chang MG. Comparison of published guidelines for management of coagulopathy and thrombosis in critically ill patients with COVID 19: implications for clinical practice and future investigations. Crit Care. 2020;24(1): 1-13. https://doi.org/10.1186/s13054-020-03273-y

37. Thachil J, Tang N, Gando S, et al. ISTH interim guidance on recognition and management of coagulopathy in COVID-19. J Thromb Haemost. 2020;18(5):1023-1026. https://doi.org/10.1111/jth. 14810

38. Bikdeli B, Madhavan MV, Jimenez D, et al. COVID-19 and thrombotic or thromboembolic disease: implications for prevention, antithrombotic therapy, and follow-up: JACC State-of-the-Art Review. J Am Coll Cardiol. 2020;75(23):2950-2973. https://doi.org/10.1016/j.jacc.2020.04.031

39. Piagnerelli M, Cauchie $\mathbf{P}$, Wautrecht JC. Optimizing the risk-benefit balance of thromboprophylaxis in critically ill patients with coronavirus disease 2019. Crit Care Med. 2020;48(10):e988-e989. https://doi.org/ 10.1097/CCM.0000000000004509

40. Maatman TK, Jalali F, Feizpour C, et al. Routine venous thromboembolism prophylaxis may be inadequate in the hypercoagulable state of severe coronavirus disease 2019. Crit Care Med. 2020;48(9):e783-e790. https://doi.org/10.1097/CCM.0000000000004466

Publisher's Note: Springer Nature remains neutral with regard to jurisdictional claims in published maps and institutional affiliations. 